\title{
ENTRE LO SAGRADO Y LO PROFANO: \\ LITERATURA, BARBARIE Y SILENCIO INMACULADO EN NOCTURNO DE CHILE DE ROBERTO BOLAÑO
}

\author{
POR \\ ENRIQUe SCHMUKLER \\ Universidad Nacional de La Plata - CONICET
}

\section{LA SOTANA}

La contradicción entre lo sagrado y lo profano domina la conciencia del personaje principal de Nocturno de Chile (2000). En la primera escena, Sebastián Urrutia Lacroix, un religioso en sus horas finales, rememora una cena en el campo del celebérrimo crítico literario Farewell. En el trayecto en tren a Chillán, el pueblo chileno donde se encuentra la finca, el cura no se decide entre vestir sotana o ropa de seglar: "Y cuando llegó el día señalado todo en mi alma era confusión e incertidumbre, no sabía qué ropa ponerme, si la sotana o ropa de seglar, y si me decidía por la ropa de seglar no sabía cuál escoger, y si me decidía por la sotana me asaltaban dudas acerca de cómo iba a ser recibido" (Bolaño, Nocturno 15). Después de bajar del tren, Urrutia Lacroix es conducido en taxi a una aldea llamada Querquén. Mientras aguarda en la plaza central el carruaje que lo conducirá a destino, lo sorprenden los chillidos de una bandada de pájaros negros que levanta vuelo detrás de una arboleda. Para el cura parecen convocar el nombre de una "aldea perdida" (17), aunque también cree escuchar la pregunta repetida "quién, quién, quién", como si entre Querquén y el graznido de los pájaros se abriera el abismo iterativo de una incógnita ominosa sobre su identidad; tan terrible que, para conjurar el efecto de inquietante extrañeza que le produce, decide sentarse a rezar para "componer una figura más acorde con lo que yo era o lo que yo en aquel tiempo creía ser":

Virgen María, no desampares a tu siervo, murmuré, mientras los pájaros negros de unos veinticinco centímetros de alzada decían quién, quién, quién, Virgen de Lourdes, no desampares a tu pobre clérigo, murmuré, mientras unos pájaros minúsculos, de colores magenta y negro y fucsia y amarillo y azul ululaban quién, quién, quién, al tiempo que un viento frío se levantaba de improviso helándome hasta los huesos. (Nocturno 17) 
Al aproximarse al fundo de Farewell, el miedo va alertando a Urrutia Lacroix sobre un inminente pasaje al otro lado del territorio sagrado; en su caso, el credo católico. Algo similar a lo que sostiene Mircea Eliade: el hombre religioso "rompe" la homogeneidad "neutra" y "sin orientación" del espacio profano y es a través de esa fractura que crea su mundo "porque es ella la que descubre el 'punto fijo', el eje central de toda orientación futura" (25). Para Eliade, la oposición tácita entre el "territorio habitado y el espacio desconocido e indeterminado que las rodea" (32) es la característica determinante de las sociedades tradicionales que "crean Mundo" a través de la sacralización de ciertos territorios:

[...] el primero [el territorio habitado] es el "Mundo" (con mayor precisión: "nuestro mundo"), el Cosmos; el resto, ya no es un Cosmos sino una especie de "otro mundo", un espacio extranjero, caótico, poblado de larvas, de demonios, de "extranjeros" (asimilados, por otra parte, a los demonios y a los fantasmas). A simple vista, esta ruptura en el espacio parece obedecer a la oposición entre un territorio habitado y organizado, es decir, "cosmizado", y el espacio desconocido que se extiende más allá de sus fronteras: tenemos, por un lado, un "Cosmos" y, por otra parte, "un Caos". Pero veremos que si todo territorio habitado es un "Cosmos", lo es justamente porque previamente ha sido consagrado; porque, de una u otra manera, es obra de los dioses o se comunica con su mundo. El "Mundo" (es decir: "nuestro mundo") es un universo en cuyo interior lo sagrado ya se manifestó, un mundo donde, por consiguiente, la ruptura de niveles ha sido posible y se puede repetir. (Eliade 32, traducción mía)

El caos, la desorientación, los demonios y los fantasmas. En suma: la terra incognita se corresponde con un espacio no consagrado y con un mundo indócil del cual el hombre no ha podido adueñarse aún. En Nocturno de Chile, esas experiencias desconocidas y aterradoras ocurren en un lugar y orbitan en una galaxia: la finca de Farewell, donde todo asunto es literario. Para el moribundo narrador de la novela, visitarla poseyó, en su juventud, el valor ritual de un bautismo no-religioso, un "bautismo en el mundo de las letras" (34). De ahí que lo profano coincida con aquello inasible que en el texto se representa como literatura. De hecho, la finca lleva el nombre de un texto clásico del tournant du siècle: Là-bas de Joris-Karl Huysmans; territorio por explorar, el fundo de Farewell también es un allá lejos donde las embestidas demoníacas de lo literario se suceden antojadizas.

Con todo, si fuera un espacio por conquistar la literatura sólo se dejaría sacralizar al precio de perder su radicalidad insumisa. Por eso, el sentido del recorrido que lleva a cabo Urrutia Lacroix no es exactamente el mismo que el que describe Eliade. Es más bien el inverso: al aceptar la invitación de Farewell, el clérigo solo conseguirá desacralizar o profanar su mundo. Y nada más. También en esta transacción la sotana, junto con la desnudez, desempeña un papel clave.

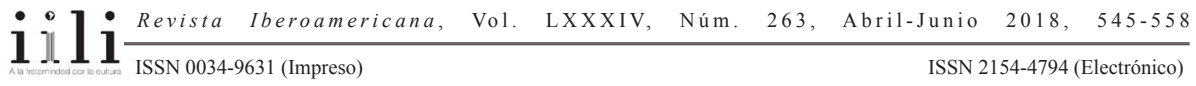




\section{DESNUDEZ}

La desnudez asoma con llamativa frecuencia durante esa primera visita del cura al fundo de Farawell. A menudo vinculada con la imagen que el sacerdote tiene de la literatura y sus autores, se la menciona por primera vez poco antes de la primera cena, cuando Urrutia Lacroix descubre por casualidad a Pablo Neruda hablándole a la luna:

Allí estaba Neruda recitando versos a la luna, a los elementos de la tierra, y a los astros cuya naturaleza desconocemos mas intuimos. Allí estaba yo, temblando de frío en el interior de mi sotana que en aquel momento me pareció de una talla muy por encima de mi talla, una catedral en la que yo habitaba desnudo y con los ojos abiertos. (24)

Cubierto por una sotana demasiado grande para su talle, Urrutia Lacroix abre bien los ojos y cae en la cuenta por primera vez en su vida de su propia desnudez. En la escena siguiente, en un intervalo de la sobremesa de aquella misma comida de bienvenida, Bolaño vuelve a aludir a la desnudez con que Urrutia Lacroix hace frente a la inminencia de la literatura. El cura sale una vez más a la terraza, esta vez a tomar aire tras sufrir una ligera indisposición estomacal. Luego de unos minutos en soledad entra en escena "la figura homérica de Farewell" (25). Y después vuelve a asomarse por allí Neruda. Se produce entonces una escena de seducción homoerótica alternada con referencias literarias y con el poeta chileno como testigo ignorante. Farewell comienza a sonsacarle al cura lecturas; pregunta por poetas populares italianos mientras, entre respuesta y respuesta, toma a su interlocutor de la cintura, por detrás. Al final las manos de Farewell bajan todavía más, hasta las nalgas, apretujándolas:

Y entonces la mano de Farewell descendió de mi cadera hacia mis nalgas y un céfiro de rufianes provenzales entró en la terraza e hizo revolotear mi sotana negra y yo pensé: El segundo ¡ay! ha pasado. Mira que viene enseguida el tercero. Y pensé: Yo estaba de pie sobre la arena del mar, y vi surgir una Bestia. Y pensé: Entonces vino uno de los siete Ángeles que llevaban las siete copas y me habló. Y pensé: Porque sus pecados se han amontonado hasta el cielo y Dios se ha acordado de sus iniquidades. (27)

La visión febril de "la Bestia" y de un acopio de pecados surge de la profanación de la sotana por un "céfiro de rufianes provenzales"; son esos rufianes (que en verdad son poetas; rufianes poetas) quienes estimulan lo que palpita con fuerza cada vez que el crítico literario accede a las nalgas de Urrutia Lacroix (la lujuria culposa es también la del cura).

En el comentario que Giorgio Agamben hace del escrito Theologie des Kleides (Teología del vestido) del teólogo alemán Erik Peterson, la hipótesis que explica el pecado se modula a partir de la relación que el dispositivo teológico establece entre

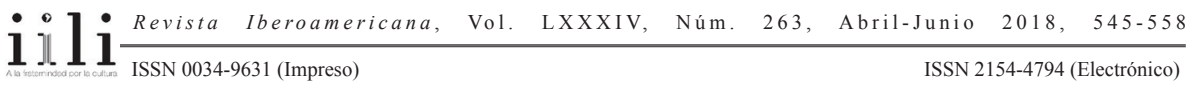


vestido y desnudez. Uno de los fragmentos del texto de Peterson que comenta Agamben refiere que "se da desnudez solo después del pecado. Antes del pecado había ausencia de vestidos [Unbekleidetheit], pero esta aún no era desnudez [Nacktheit]. La desnudez presupone ausencia de vestido, pero no coincide con ella" (Desnudez 84). Precisa también que:

[...] El drástico giro de la naturaleza humana a través del pecado conduce al 'descubrimiento' del cuerpo, a la percepción de su desnudez. Antes de la caída, el hombre existía para Dios de tal modo que su cuerpo, aun en ausencia de todo vestido, no estaba 'desnudo'. Ese 'no estar desnudo' del cuerpo humano incluso en la aparente ausencia de vestidos se explica por el hecho de que la gracia sobrenatural circundaba a la persona humana como un vestido. El hombre no solo se rencontraba en la luz de la gloria divina: estaba vestido de la gloria de Dios. A través del pecado, el hombre pierde la gloria de Dios, y en su naturaleza ahora se hace visible un cuerpo sin gloria: el desnudo de la pura corporeidad, el desnudamiento de la pura funcionalidad, un cuerpo al que le falta toda nobleza, puesto que la dignidad última del cuerpo estaba encerrada en la perdida gloria divina. (85)

Pero Agamben deduce una contradicción en la hipótesis del teólogo. Porque si inclusive antes del pecado original Dios cubrió al hombre con un "vestido glorioso", "si ya antes del pecado había necesidad de cubrir el cuerpo humano con el velo de gloria", esto quiere decir que "a la beata e inocente desnudez paradisíaca le preexistía otra desnudez, esa 'corporeidad desnuda' que el pecado, al quitar el vestido de gracia, deja aparecer despiadadamente" (86). De lo que resulta la necesaria preexistencia de eso vergonzante que el vestido de luz tiene por función ocultar, puesto que el pudor divino jamás hubiera existido sin la hipótesis de esa "“corporeidad desnuda', en sí privada de gracia, que la pérdida del vestido hace aparecer ahora en su 'pura funcionalidad' biológica, 'con todos los signos de su sexualidad', como un cuerpo al que le falta toda nobleza" (86).

En Nocturno de Chile el riesgo de un desnudamiento así, "innoble", bien podría situarse en el origen de las alarmas que paralizan a Urrutia Lacroix antes de ingresar al universo de la literatura. De todos modos, en la conciencia del sacerdote, la desnudez terminará por declararse más temprano que tarde. De hecho, algo así como una aviesa desnudez se manifiesta cuando, en la terraza de la casa principal, debajo de su sotana imponente como una catedral, el cura no puede reprimir la seducción casi orgásmica que le producen las tentativas del crítico. Pero también cuando Urrutia Lacroix descubre a dos niños en medio del campo, un niño y una niña que "cual Adán y Eva se afanaban desnudos a lo largo de un surco de tierra”, razón por la cual el sacerdote se derrumba en una "náusea" y en "el vacío, un vacío intestinal, un vacío hecho de estómagos y entrañas" (29).

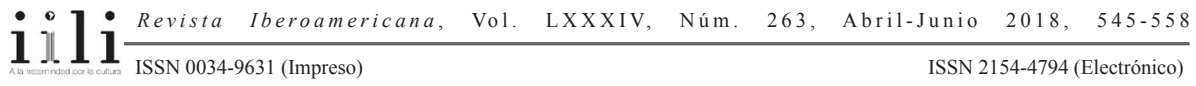


En la tradición cristiana, la desnudez infantil se asocia con una desnudez "sin vergüenza" que remite, a su vez, a la "desnudez paradisíaca": "Aunque signados por el pecado original, los niños, al no ver la desnudez, moran en una suerte de limbo, no conocen la vergüenza que sanciona, según Agustín, la aparición de la libido" (Desnudez 106). Por otra parte, la nostalgia de ese modo pueril de percibir el cuerpo es un motivo recurrente en los Evangelios y le dio sentido, durante los primeros dos siglos de cristianismo, al rito bautismal cuando este aún no se practicaba únicamente a los neonatos.

Las nauseas y la "caída" de Urrutia Lacroix al ver a los niños desnudos tienen relación, sin duda, con la turbación que produce enfrentarse a una desnudez sin vergüenza (o sin vestido). Y cobran fuerza ante el singular bautismo que el cura recibe durante el fin de semana en el campo; singular porque si el bautismo cristiano se define como un rito mediante el cual, revestido por la gracia divina, el hombre pretende recuperar su inocencia perdida, al tratarse en este caso de un bautismo literario, la desnudez no borra los pecados, sino al revés: al desnudo, la pérdida de la inocencia (la culpabilidad) se reproduce en el frenesí desbordante del relato.

\section{Pecados}

Pero el bautismo en el mundo de las letras desnuda otra forma de contradicción entre lo sagrado y lo profano; "viste" al cura con las culpas que revelan la ambivalencia ética que jalona su vida y que no pueden ser desligadas de su rol de literato. De entrada, Bolaño propone leer oblicuamente este rasgo de Urrutia Lacroix mediante una "ficción de la Ocupación de París" - presentada bajo la forma de una anécdota contada por el escritor chileno Salvador Reyes en una de las reuniones organizadas por Farewell-en la que el personaje central es Ernst Jünger. La descripción de ese encuentro adjetiva laberínticamente la figura del escritor alemán. Reyes -escritor y diplomático de la embajada chilena- es presentado ante Jünger por una condesa italiana que lo guía a través de "varios salones" que se abren caleidoscópicamente "como rosas místicas" (38). La imagen de un laberinto cuyo centro es Jünger (“[...] y en el último salón había un grupo de oficiales de la Wehrmacht y varios civiles y el centro de atención de toda esta gente era el capitán Jünger"(38)) no carece de significado ni de importancia; es el telón de fondo sobre el cual Bolaño proyecta la sombra del propio Urrutia Lacroix.

En un perfil publicado en su libro El pase del testigo (2001), Edgardo Cozarinsky describe a Jünger como a "un hombre de cultura que se halla del lado malo de la historia" (Cozarinsky 90). Y continúa:

[...] alguien que no es nazi pero que, por un sentimiento de lealtad a un ejército donde veinticinco años antes vivió sus primeras y embriagadoras aventuras, lleva el uniforme de la Wehrmacht y se deja enviar como parte de las fuerzas de ocupación a un país que

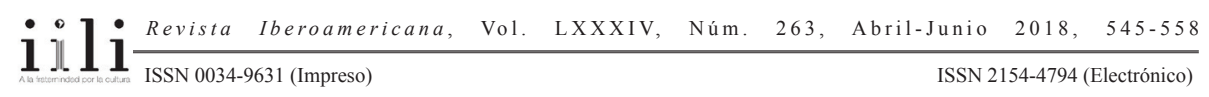


admira; [...] alguien que prefiere no discernir hasta qué punto defiende el honor de su patria al no abandonar ese uniforme y hasta donde acepta la solución más cómoda. (91)

Cozarinsky concluye con una reflexión y una pregunta: "La mentira íntima del hombre de cultura, que cree rescatar una parcela de independencia personal ies acaso menos mezquina que la mentira grosera, colectiva, de la propaganda? (91). Pregunta y reflexión son válidas también para Urrutia Lacroix, un personaje que, probablemente, se inspira tanto en Jünger como en su "referente pseudo-real encubierto" (Solotorevsky 49): el cura, crítico y poeta chileno José Miguel Ibañez Langlois. Tanto en el cura de ficción como en el capitán (escritor) de la Wehrmacht, la literatura pretende pasar indemne, sin siquiera rozarlos, por los acontecimientos de la historia. Así, la parcela de independencia personal de Urrutia Lacroix equivale a un mundo "en donde la literatura sí que era un camino de rosas y en donde el saber leer no carecía de mérito y en donde el gusto primaba por encima de las necesidades y obligaciones prácticas" (Bolaño, Nocturno 15).

Tal vez no exista en la novela episodio tan ilustrativo sobre el uso que hace Urrutia Lacroix de la literatura como el triunfo de Allende en las elecciones de 1970. Al conocer la noticia, Urrutia Lacroix se dice a sí mismo "que sea lo que Dios quiera" y se impone una tarea: "yo voy a releer a los griegos", piensa. Y después, Bolaño escribe una de las escenas más vertiginosas de la novela en donde la relectura de los clásicos -Bolaño enumera en un fárrago infatigable autores y obras de la Grecia y Roma antiguas- es interrumpida por la alusión a algunos de los episodios políticos e históricos que van del triunfo de la Unidad Popular al golpe de Pinochet y el suicidio de Allende:

Y después vino el golpe de Estado, el levantamiento, el pronunciamiento militar, y bombardearon la Moneda y cuando terminó el bombardeo el presidente se suicidó y acabó todo. Entonces yo me quedé quieto, con un dedo en la página que estaba leyendo, y pensé: qué paz. (98-99)

En la concepción literaria de Urrutia Lacroix la historia irrumpe profanadora mientras los clásicos -la Literatura con mayúscula- funcionan como una referencia que ofrece un orden dentro del caos inexorable de lo real. Claro que luego del golpe de Pinochet el caos (la historia), es neutralizado a la fuerza, y el mal -el sustrato inadmisible de la historia- reaparece como el reverso maldito de la literatura. Porque sus lecturas se vuelven finalmente inocuas cuando "cansado de leer a tantos griegos" decide volver a leer a los contemporáneos y su poesía "de angélica” "se tornó demoníaca” (101):

Tentado estuve, muchos atardeceres, de mostrarle mis versos a mi confesor, pero no lo hice. Escribía sobre mujeres a las que zahería sin piedad, escribía sobre invertidos, sobre niños perdidos en estaciones de trenes abandonadas. Mi poesías siempre había 
sido, para decirlo en una palabra, apolínea, y lo que ahora me salía más bien era, por llamarlo tentativamente de algún modo, dionisíaco. Pero en realidad no era poesía dionisíaca. Era rabiosa. (101)

El mal toma de improviso la literatura del poeta religioso; se aloja en su interior o, mejor dicho, desde su interior. Algo muy parecido es lo que ocurre en las tertulias literarias que se llevaban a cabo en la casa de María Canales, una joven novelista chilena casada con Jimmy Thompson, un estadounidense agente de la DINA (la policía secreta chilena). En las soirées de Canales, los asistentes, el contexto histórico, la razón de por qué se llevaban a cabo, todo interpela el modo en que la literatura, en Nocturno de Chile, hunde sus raíces en (es un documento de) la barbarie (Benjamin). Porque en esa especie de "crónica de la vida literaria" con que las describe Urrutia Lacroix (que era invitado asiduo) no hay vacilaciones: las reuniones en lo de Canales tienen lugar en el momento en que, en Chile, comienza a imperar el estado de sitio. Escribe Bolaño:

El problema, aparte del hecho insoslayable de que muchos amigos se habían marchado del país por problemas a menudo más de índole personal que política, radicaba en el toque de queda. ¿Dónde se podían reunir los intelectuales, los artistas, si a las diez de la noche todo estaba cerrado y la noche, como todo el mundo sabe, es el momento propicio de la reunión y de las confidencias y del diálogo entre iguales? (124)

Como los Clásicos, como el complejo desdoblamiento que vive Jünger en sus diarios parisinos, las soirées de Canales abren en la historia una especie de recinto sagrado, un "estado de excepción" (Agamben, Homo Sacer II). Sin embargo, como ocurre con los poemas "demoníacos" del cura, "lo nocturno" de Chile a que hace referencia el título de la novela consigue penetrar en "el esplendor nocturno" (143) de esa lujosa residencia de las afueras de Santiago; o, mejor dicho, en el sótano de la casa donde un artista de vanguardia descubre "iluminado por una débil bombilla" (140) "a un hombre atado a una cama metálica", con "los ojos vendados". En efecto, el subsuelo es la zona de injerencia del marido de la anfitriona (donde se encarnizaba en la tortura de opositores políticos) y, en cierta forma, de donde brota la oscuridad de la historia, implícita en los diálogos literarios de la planta baja. Porque esa tenebrosa oscuridad es la que miran los ojos robados del otro Sebastián de la novela, uno de los hijos de la pareja (doble desnudo e infantil del personaje principal), en cuyo rostro Sebastián Urrutia Lacroix sospechosamente no halla rasgos de parentescos con sus progenitores:

Me fijaba, por ejemplo, en el niño Sebastián, mi pequeño tocayo, y en su carita flaca. [...] El niño me contempló con sus grandes ojos azules. Puse mi mano sobre su cara. Qué carita más fría. De pronto sentí que los ojos se me estaban llenando de lágrimas. [...] y tuve la impresión de que esos grandes ojos veían lo que no querían ver. (129) 
Finalmente, la relación entre la literatura y la barbarie tiene otro hito en la novela. Siempre bajo la dictadura, le encomiendan al cura una misión de riesgo: darles clases de marxismo a Augusto Pinochet y a sus colaboradores de la Junta Militar. Cuando el asunto sale a la luz, el cura, para su sorpresa, no recibe crítica alguna por su actuación, aun cuando su función pedagógica tenía por objetivo -le hace decir Bolaño a Pinochet en uno de los diálogos con Urrutia Lacroix-“comprender a los enemigos de Chile, [...] saber cómo piensan, [...] imaginar hasta dónde están dispuestos a llegar" (118).

Araíz de esto, Urrutia Lacroix reflexiona en un tono melancólico sobre la indolencia del medio intelectual chileno. Descubre "con estupor" que en el Chile de la dictadura de Pinochet, "a nadie le importaba un pepino" y que, por tal motivo, "las figuras hieráticas que poblaban la patria se dirigían, inconmovibles, hacia un horizonte gris y desconocido en el que apenas se vislumbraban unos rayos lejanos, unos relámpagos, unas humaredas" (120, énfasis mío). ${ }^{1}$ Pero el cura tampoco es ajeno a esa atmósfera de indolencia general pese a que las figuras sagradas de Chile se precipitan en un horizonte apocalíptico. Y cuando Urrutia Lacroix comienza a gozar por primera vez en su vida de un insospechado reconocimiento como poeta, la sotana-superficial, revoloteando en el aire acondicionado y entre las puertas automáticas de los aeropuertos internacionalesdesfila en la mundanidad de lo que Barthes llamó el sistema de la moda.

La sotana, una vez más, cumple la función de cubrir el cuerpo desnudo y ocultar; pero, al mismo tiempo, lo hace profanándose o, mejor dicho, secularizándose; se pone "de moda" (en evidencia). Bolaño escribe:

Y llegó mi hora de pasear por los aeropuertos del mundo, entre elegantes europeos y graves norteamericanos (que parecían, además, cansados), entre los hombres mejor vestidos de Italia, Alemania, Francia e Inglaterra, caballeros que era un gusto ver, y yo por allí pasaba, con mi sotana revoloteando por el aire acondicionado o por las puertas automáticas que se abrían de repente, sin causa lógica, como si presintieran la presencia de Dios, y todos decían al ver mi humilde sotana al aire allí va el padre Sebastián, el padre Urrutia [...] (122)

Es decir, la frivolidad religiosa es el colofón de una reflexión sobre los años chilenos de "acero y silencio" (121) que lleva al extremo el cruce entre la cultura y el mal. En este sentido, Nocturno de Chile revisita uno de los motivos insistentes de la narrativa de Bolaño; además, este aparece vinculado a una institución igualmente emblemática dentro de la obra del chileno: el salón literario de "derecha", cuya anfitriona inaugural es Edelmira Thompson de Mendiluce, el trasunto oblicuo, paródico, irrisorio y nazi de Victoria Ocampo, que inaugura la serie de biografías imaginarias de la enciclopedia

Esta imagen remite al desenlace de la novela anterior de Bolaño, Amuleto (1999) en donde los jóvenes poetas latinoamericanos se sacrifican y marchan ciegos rumbo al abismo (Amuleto 152 y ss). 
infame La Literatura Nazi en América (1996). En el caso de los cursos de marxismo a Pinochet y su séquito, la barbarie deja de funcionar desde el subsuelo, en las sombras (en el sótano) o como parodia, para equivalerse en la superficie (en la sotana) a la transmisión de la cultura que reciben los representantes gubernamentales de esa misma barbarie.

\section{EL JOVEN ENVEJECIDO}

Ocultar -justificarse- la contradicción entre literatura, religión y barbarie es la razón fundamental del relato que comienza Urrutia Lacroix al mismo tiempo que la novela de Bolaño. Esa necesidad de reparación o de desagravio tiene en el silencio inmaculado su garantía última. El silencio es la responsabilidad sagrada que rige la vida cristiana de Urrutia Lacroix puesto que, en su concepción pragmática, el cura suspende en el silencio el juicio ético, demorado en la espera del Juicio Final; el inapelable procedimiento judicial de Dios:

Hay que ser responsable. Eso lo he dicho toda mi vida. Uno tiene la obligación moral de ser responsable de sus actos y también de sus palabras e incluso de sus silencios, porque también los silencios ascienden al cielo y los oye Dios y solo Dios los comprende y los juzga, así que mucho cuidado con los silencios. Yo soy responsable de todo. Mis silencios son inmaculados. Que quede claro. Pero sobre todo que le quede claro a Dios. Lo demás es prescindible. Dios no. (11)

El silencio es inmaculado porque para el cura es el punto de referencia nodal de su relato; y supone algo del orden de lo no dicho que nadie excepto Dios está en condiciones de comprender ni juzgar. Sin embargo, el narrador -no Urrutia Lacroix, por supuesto, sino a pesar suyo- deja aparecer a un interlocutor fantasmático: el llamado "joven envejecido". Figura, personaje o simplemente voz (bien podría ser un interlocutor que sólo funciona dentro de una conciencia culposa), es en verdad un "supuesto interlocutor" sin rasgos definidos, pero con una voz. Y es el efecto de voz, de hecho, lo que vincula a esta obra de Bolaño con una serie de novelas de la primera mitad del siglo XX que ponen en crisis la noción de sujeto; textos en los cuales, a través de personajes que no costaría mucho identificar como "locutores", la voz tiende a independizarse del sujeto al que supuestamente debe su identidad. En un libro sagaz sobre este tema, Vers une littérature de l'épuisement (2004), Dominique Rabaté señala que en textos como La caída (1956) de Camus, Compañía (1979) de Beckett o El hablador (1946) de des Fôrets, la puesta en escena del "efecto de voz" se constituye en la mostración narrativa de la reconstrucción imposible de una voz y de un sujeto; novelas de la crisis de la novela en las que un personaje principal y narrador habla pero, al hacerlo (a raíz de que toma la palabra) comienza a extraviarse.

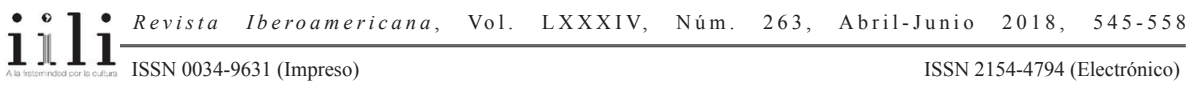


La voz se libera del sujeto borrando los acontecimientos y el interlocutor imaginario a quien supuestamente se dirige.

En este sentido, el "joven envejecido" remite al tipo de "receptores" que ponen en escena las "novelas de voz"; máscaras subjetivas de un personaje cuya locución ansía "un monólogo exterior que busca la presencia ausente del otro para recibir la confesión” (Rabaté 18). Al inmiscuirse en la conciencia de Urrutia Lacroix, hace gala de un tesón irreverente; su confianza, que para el sacerdote es temeridad desvergonzada, se exhibe con blasfema prodigalidad. Allí radica su poder de doppelgänger profano de Urrutia Lacroix. Si lo sagrado se esgrime en la novela para vestir u ocultar, el emisario inopinado engaña al cura y, colándose debajo de su sotana, lo obliga a tomar la palabra haciendo caso omiso del silencio que no se debe violar:

\begin{abstract}
Ahora me muero, pero tengo muchas cosas que decir todavía. Estaba en paz conmigo mismo. Mudo y en paz. Pero de improviso surgieron las cosas. Ese joven envejecido es el culpable. Yo estaba en paz. Ahora no estoy en paz. Hay que aclarar algunos puntos. Así que me apoyaré en un codo y levantaré la cabeza, mi noble cabeza temblorosa, y rebuscaré en el rincón de los recuerdos aquellos actos que me justifican y que por lo tanto desdicen las infamias que el joven envejecido ha esparcido en mi descrédito en una sola noche relampagueante. Mi pretendido descrédito. (Bolaño, Nocturno 11)
\end{abstract}

El joven envejecido, entonces, es un interlocutor fantasma que estimula la confesión de Ibacache y sus "ansias de narrar" (Solotorevsky 53). Y es su "presencia ausente" la que desplaza el dispositivo religioso de modo tal que el clérigo termina definitivamente fuera del recinto sagrado que protege con el secreto y el silencio la confesión religiosa. Sin embargo, el silencio inmaculado sigue funcionando como garantía. De modo que otro dilema nace y rápidamente se vuelve irresoluble. Ese dilema es, como los otros, entre lo sagrado y lo profano. Se podría expresar en estos términos: ¿cómo decir la verdad para desagraviarse y al mismo tiempo resguardar el silencio? O bien: ¿cómo justificarse guardando silencio y cómo guardar silencio hablando?

LA VOZ, LA DIGRESIÓN, LA HISTORIA

¿Qué tipo de figura estilística permite al hablante decir sin decir? Al referirse a la digresión en Proust (se entiende: en La Recherche), Pierre Bayard se retrotrae a la etimología de digredior: "Dis-gradior o caminar fuera del camino recto que, por ejemplo, se ha trazado". (Bayard 18, traducción mía). A menudo, afirma, esta idea reaparece en las metáforas que acompañan la digresión "junto con otras imágenes como la de la línea o el hilo que se rompe o se deja atrás" (18). Porque otro de los índices -que, por obvio, ni siquiera habría que detenerse en él-es el de la longitud de la frase. Las

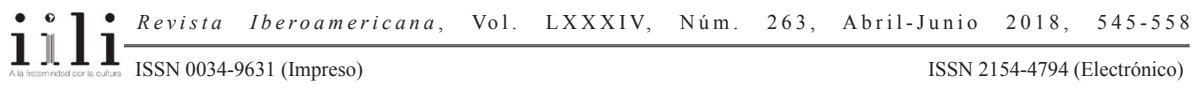


digresiones, dice, suelen desarrollarse (y en Proust lo hacen, definitivamente) en largas frases que discurren o derivan como si se fugaran.

En la novela de Bolaño, la única salida que encuentra el cura a su dilema entre hablar o resguardarse en el silencio de Dios es hacia delante. Una característica formal del texto sirve de argumento para abonar esta hipótesis: la novela entera se desarrolla en dos párrafos. El primero, desde el comienzo hasta la penúltima oración en donde Bolaño inserta un punto y aparte. Y luego sí, la oración final; la escatológica, apocalíptica "Y después se desata la tormenta de mierda" (150). Entretanto, Urrutia Lacroix insiste en varios pasajes de la novela en frases como estas: "aclarar algunos puntos" (11), "actos que me justifican" (12), "infamias que el joven envejecido ha esparcido en mi descrédito" (12). Pero nunca precisa cuáles son esas infamias, ni los puntos ni los actos que necesita aclarar. Pese a todo, se deja inferir que esas expresiones refieren a ciertos actos u omisiones de los cuales es responsable: "Yo soy responsable de todo", arrecia el cura. Y sin embargo, en lugar de develar ese "todo", insiste una y otra vez en que "uno tiene la obligación moral de ser responsable de sus actos y también de sus palabras y de sus silencios" (11).

Este oscilar deliberadamente inconducente (a los efectos de detener su marcha) define la opción de Urrutia Lacroix por la digresión. Y corre a la par de su propia concepción de la historia: irreversible, representada geométricamente (la única manera de asir el tiempo, según Agamben) por la línea recta. Porque en aras de garantizar el silencio inmaculado, el sacerdote recurre a la Historia en varios pasajes de la novela. E inclusive antes de que se la mencione explícitamente, alude a una particular noción del tiempo histórico. Por ejemplo sobre el final, cuando en años democráticos el cura visita por última vez la casa de Canales (ya tenebrosamente célebre en "virtud" de su oscuridad develada): al despedirse, enojado, de su anfitriona oscura y banal, se sube a su coche y toma la autopista (otra línea recta). Se abandona entonces a un flujo de conciencia en el cual el tiempo es caracterizado como "la gran máquina de moler carne del tiempo":

[...] y mi auto entró otra vez en el túnel del tiempo, en la gran máquina de moler carne del tiempo [...]. Ahora el enfermo soy yo. Mi cama gira en un río de aguas rápidas. Si las aguas fueran turbulentas yo sabría que la muerte está cerca. Pero las aguas sólo son rápidas, por lo que aún albergo alguna esperanza. Desde hace mucho el joven envejecido guarda silencio. Ya no despotrica contra mí ni contra los escritores. ¿Tiene esto solución? [...]. (148)

Para representar el tiempo Urrutia Lacroix recurre a la metáfora de la autopista que, a su vez, rápidamente se transforma en río. La digresión de la voz de Urrutia Lacroix remeda el discurrir extático del río. Y la voz-río descansa en un no-dicho esencial. Además, la "gran máquina de moler carne del tiempo" sugiere el carácter destructor de

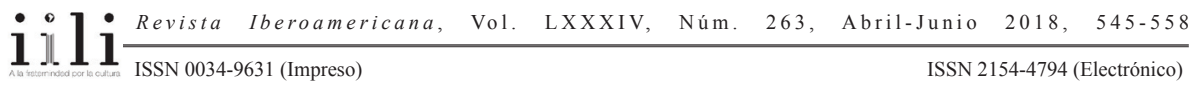


la concepción cristiana de la temporalidad, concebida como una "sucesión de instantes puntuales" (Agamben, Enfance 168, traducción mía). Curiosamente, dice Agamben, "pese a su aparente desprecio del "siglo", es el cristianismo el que sentó las bases de una experiencia de la historicidad; y no el mundo antiguo que parece sin embargo tan atento a los acontecimientos mundanos" (167). Y añade que si la representación antigua del tiempo es un círculo, "la imagen que orienta la conceptualización cristiana es la de la línea recta":

Al contrario del helenismo, el mundo, para el cristiano, fue creado en el tiempo y debe terminar en el tiempo. Por un lado, el relato del Génesis; por otro, la perspectiva escatológica del Apocalipsis. Y la creación, el Juicio final, el período intermedio que transcurre entre estos dos acontecimientos son únicos. Este universo creado y único, que comenzó, dura y terminará en el tiempo, es un mundo finito y limitado entre los dos bordes de su historia. No es ni eterno ni infinito en su duración, y los acontecimientos que se desarrollan en él no se repetirán jamás. (Enfance 166-67, traducción mía)

El carácter destructor del tiempo y de la historia se cristaliza, hacia el desenlace de Nocturno de Chile, en tanto que historia irreversible. En el delirio senil del protagonista, el recuerdo de la sala de torturas, sumado a la reivindicación de un tiempo cristiano que termina en el Juicio final y el Apocalipsis, conducen a Urrutia Lacroix a considerar la historia como una digresión: una perpetua fuga hacia delante. Una historia representada como una línea recta o un río cuyo cauce ya no puede detenerse. Y es en ese punto, al final de la novela, cuando esa figura extraña termina revelándose ominosa (en el sentido freudiano: extrañamente familiar o familiarmente extraña):

Y entonces me pregunto, ¿dónde está el joven envejecido?, ¿por qué se ha ido?, y poco a poco la verdad comienza a ascender como un cadáver. Un cadáver que sube desde el fondo del mar o desde el fondo de un barranco. Veo su sombra que sube. Su sombra vacilante. Su sombra que sube como si ascendiera por la colina de un planeta fosilizado. Y, entonces, en la penumbra de mi enfermedad, veo su rostro feroz, su dulce rostro, y me pregunto: ¿soy yo el joven envejecido? ¿Esto es el verdadero, el gran terror, ser yo el joven envejecido que grita sin que nadie lo escuche? ¿Y que el pobre joven envejecido sea yo? (149-150)

El diálogo imaginario entre Urrutia Lacroix y el joven envejecido se exhibe primero como monólogo en voz alta y luego -cadáver flotando en el agua-como confesión: la verdad (la verdad de la novela) se revela escatológica, un espejo abismal en el que se refleja la conciencia tortuosa de Urrutia Lacroix. Agamben afirma en otro pasaje de su libro que la eternidad, como régimen de la divinidad "tiende a viciar de nulidad la experiencia humana del tiempo, imponiéndole su círculo de inmovilidad" (Enfance 168). Entre la eternidad inmóvil (el silencio inmaculado) y el tiempo histórico (secular,

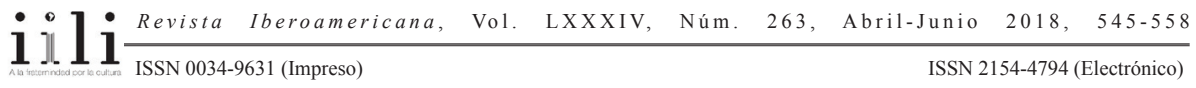


profano), el cura de Nocturno de Chile es "víctima" de la verdad profana de la historia, que sale a la superficie y se muestra tal cual es: un cadáver que fluye debajo de las palabras hasta el instante de su revelación.

\section{BibliografíA}

Agamben, Giorgio. Desnudez. Buenos Aires: Adriana Hidalgo, 2011.

Enfance et histoire. París: Payot, 2002.

Etat d'exception. Hommo Sacer II, 1. Paris: Seuil, 1998.

Bayard, Pierre. Le Hors-sujet: Proust et la digression. Paris: Minuit, 1996.

Benjamin, Walter. Euvres III. París: Folio, 2004.

"Sur le concept d'histoire". Euvres III. París: Folio, 2004. 427-443.

Benmiloud, Karim y Raphël Esteve, eds. Les astres noirs de Roberto Bolaño. Bordeaux: Presses Universitaires de Bordeaux, 2007.

Benmiloud, Karim. "“Sordel, Sordello, ¿qué Sordello?”: forma y función de un leitmotiv en Nocturno de Chile». Lecturas de "Nocturno de Chile" de Roberto Bolaño. Fernando Moreno, ed. Valparaíso: Editorial PuntÁngeles - Universidad de Playa Ancha, 2014. 241-256.

Blumenberg, Hans. Naufrage avec spectateur. Paris: L'arche, 1994.

Bolaño, Roberto. Amuleto. Barcelona: Anagrama, 1999.

La literatura nazi en América. Barcelona: Seix Barral, 1996.

Nocturno de Chile. Barcelona: Anagrama, 2000.

Caillois, Roger. L'homme et le sacré. Paris: Folio, 1988.

Cozarinsky, Edgardo. El pase del testigo. Buenos Aires: Editorial Sudamericana, 2001. Eliade, Mircea. Le Sacré et le profane. Paris: Folio, 1987.

Huysmans, Joris-Karl. Là-bas. Paris: Folio Classique, 1985.

Moreno, Fernando, ed. La memoria de la dictadura: Nocturno de Chile, Roberto Bolaño, Interrupciones, Juan Gelman. Paris: Elipses, 2006.

Roberto Bolaño: la experiencia del abismo. Santiago de Chile: Ediciones Lastarria, 2011.

Nancy, Jean-Luc. La Déclosion. Deconstruction du christianisme I. Paris: Galilée, 2005. L'adoration. Déconstruction du christianisme II. Paris: Galilée, 2010.

Rabaté, Dominique. Vers une littérature de l'épuisement. París: José Corti, 2004.

Sánchez, Yvette y Roland Spiller, eds. Poéticas del fracaso. Tübingen: Gunter Narr Verlag, 2009.

Seillan, Jean-Marie. "Huysmans, un antisémite fin-de-siècle”. Romantisme 95 (1997): 113-126.

Solotorevsky, Myrna. El espesor escritural en novelas de Roberto Bolaño. Maryland: Ediciones Hispamérica, 2012.

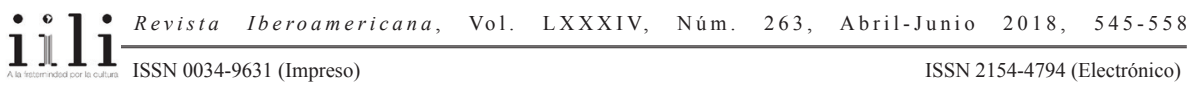


Spiller, Roland. "Roberto Bolaño: fracasar con éxito o navigare necessum est". Poéticas del fracaso. Sánchez Yvette y Roland Spiller, eds. Tübineng: Gunter Narr Verlag, 2009.143-175. 